\title{
Avaliação formal em filosofia: considerações dirigidas ao ensino médio
}

\author{
Marcelo Prates \\ Antonio Carlos Persegueiro
}

\begin{abstract}
Resumo
O texto aborda a avaliação formal e discute a retomada de sentido junto à elaboração e operacionalização desta atividade. Foca-se na Disciplina de Filosofia, ofertada no Ensino Médio (Educação Geral e Médio Profissionalizante) e sinaliza a condição de maior proximidade entre Conteúdos Programáticos e alunos(as). Para tanto, busca enaltecer o diálogo e a mediação, capacidades indeléveis ao docente, direcionando-as às atividades avaliativas. Assim procedendo, considerada a obrigatoriedade das referidas nesta e em demais fases da educação escolar, de que modo o docente poderá cultivar e, constantemente, atualizar o sentido das avaliações formais, sobretudo nas etapas de preparação e aplicação? No intuito de oferecer uma resposta propositiva, recorrer-se-á, de forma específica, às Orientações Curriculares Nacionais, na parte destinada à Filosofia. No entanto, para não incorrer em enunciações gerais, ou que fujam à questão, conjugarse-ão os apontamentos decorrentes às Diretrizes Curriculares da Educação Básica/SEED-PR. Por meio da presente convergência, serão auferidos contributos voltados ao equacionamento de demandas originadas no campo avaliativo, incontornáveis ao(as) graduandos(as) e egressos das Licenciaturas em Filosofia.
\end{abstract}

Palavras-chave: Avaliação formal. Filosofia. Ensino Médio.

\footnotetext{
* Doutor em Filosofia pela Universidade Federal do Paraná (UFPR). Professor Colaborador da Universidade Estadual do Centro-Oeste do Paraná (UNICENTRO).

${ }^{* *}$ Mestre em Filosofia pela Universidade Estadual do Oeste do Paraná (UNIOESTE). Professor colaborador da Universidade Estadual do Centro-Oeste do Paraná (UNICENTRO).
} 


\section{Considerações iniciais}

Ao visualizar a obrigatoriedade da disciplina de Filosofia na matriz curricular do Ensino Médio, reflexo de lenta e penosa mobilização, fazem-se necessários apontamentos e ponderações referentes às avaliações formais. Todavia, para serem efetuados, cumpre valorizar a progressiva implantação da disciplina nos Estados e municípios. Concomitante a esta ação, recordem-se as diversas articulações ocorridas desde os anos setenta do século XX, precedentes - e determinantes para o retorno da Filosofia. Tais fatos atestam, com efeito, o amadurecimento e disseminação de debates voltados às metodologias de ensino, aos conteúdos programáticos, recursos didáticos e, inclusive, à preparação de professores. Contudo, apesar de a Filosofia ainda não ser uma disciplina consolidada, a saber, com presença contínua nos currículos, assim como Português e Matemática, elogia-se sua crescente trajetória, sobretudo após a legitimação ocorrida em 2008. No entanto, ainda é temerário dizer algo que indique avanços se observarmos a implementação da Lei $13.415 / 2017^{1}$, a qual deixa lacunas à Filosofia, particularmente em termos de oferta estendida a todo o Ensino Médio. Para tanto, é preciso aprimorar e conferir o devido lócus à Filosofia no Ensino Médio, o que exige, então, abordar a caracterização da avaliação formal e suas peculiaridades.

Desse modo, pressuposta a necessidade das avaliações nesta e nas demais disciplinas, haja vista a fixação, o entendimento e a associação de conteúdos, o texto intenta, de um lado, aproximar assuntos e temáticas dirigidos ao público-alvo e, de outro, reavivar o sentido destas atividades imprescindíveis ao alunato. Afinal, a elaboração e aplicação de avaliações precisam corresponder às singularidades da Filosofia, dentre as quais a preservação e averiguação de problemas, o justo estabelecimento de tempo para sua realização aliada ao cultivo da reflexão e a importância do vocabulário . Também é oportuno salientar que, aliada ao material didático, envolvimento discente e atuação docente, a avaliação se eleva à instância de elemento indispensável. Quer dizer, paralela à função de detecção, a Filosofia favorece a interpretação do mundo associada aos possíveis resultados.

\footnotetext{
${ }^{1}$ Após a aprovação da Lei $n^{\text {o. }} 11.684 / 2008$ houve, pela primeira vez no Brasil, certa tranquilidade por parte dos Professores de Filosofia, pois tinham ao seu dispor 02 h/a semanais nas três séries do Ensino Médio (Educação Geral), tempo adequado à apresentação de conteúdos e à oferta de avaliações. Porém, certos Estados, alegando dificuldades financeiras, disponibilizam currículos de apenas $01 \mathrm{~h} / \mathrm{a}$ semanal! Tão grave quanto isso, o quesito tempo agora retorna, após a autoritária e irrefletida "Reforma" do Ensino Médio, veiculada pela Medida Provisória 746/2016 e, logo após, convertida em Lei. A última, além de não denominar áreas do saber como Disciplinas ou Componentes Curriculares, (o que não lhes gera um lugar na matriz curricular), estabelece que somente na primeira metade do Ensino Médio (1,5 anos) "[...] incluirá obrigatoriamente estudos e práticas de educação física, arte, sociologia e filosofia" (BRASIL, Lei 13.415/2017, Art. $3^{\circ}$., § 2). Esta adoção trará, assim como no passado recente, insegurança e prejuízos à Filosofia. Ademais, afetará a forma, os instrumentos e o tempo disponível para avaliações. Já a outra metade, ainda incerta, dependerá do arbítrio e vontade política das redes públicas, o que não garante a continuidade da Filosofia na escola.
} 
Assim procedendo, são notórias diversas propostas de ensino-aprendizagem e critérios de avaliação presentes nos vários níveis escolares. Neste âmbito, evidencia-se que a mesma disciplina pode receber tratamentos distintos, dependendo das inclinações ou tendências pedagógicas. Particularmente no Ensino Médio, existe a crescente preocupação com processos seletivos, alusivos ao ingresso na universidade. Como a avaliação referida se traduz em direcionamento de conteúdos ministrados durante as aulas, consome expressivo tempo, reduzindo - ainda mais - a formação dispensada aos adolescentes e jovens. De certo modo, embora os exames sejam necessários, constata-se a desproporcional atenção que lhes é conferida, prejudicial a tantos assuntos. Em outros termos, há a "mutilação" e a própria supressão de conteúdos humanísticos, os quais mal são introduzidos em face da ânsia de, em tais processos, auferir êxito ou elevada colocação.

Uma vez detectado o prevalecimento e ascensão dos processos seletivos no Ensino Médio, são verificadas, no tocante à Filosofia, avaliações configuradas à demanda dos testes e aplicadas por mera obrigação. Mas, se comparado aos desafios externos à escola e ao indivíduo, qual o peso e a extensão de um processo seletivo? Longe de desmerecê-lo, recorde-se a sua transitoriedade e papel real: averiguar a aprendizagem, dificuldades e possíveis avanços. Diante da desconsideração de conteúdos essenciais e complementares, os quais são subjugados, há, então, a necessidade de perpassar os (nem sempre produtivos) prevalecimentos e arbitrariedades dos exames.

A este respeito, aliada à transposição didática, está a reconsideração das avaliações, e não apenas em sua operacionalização. Apesar de ocorrerem deficiências no preparo, visualiza-se, em contrapartida, o interesse em exercícios e provas reflexivo - ainda que em menor número promotores da crítica e instigadores do autoconhecimento. Paralelo às avaliações concebidas e efetuadas a contento, elogia-se, no caso do Estado do Paraná, a oferta de livros didáticos aos Colégios Públicos, seguida do aumento de títulos. O uso dessas fontes favorece o aprimoramento de competências e habilidades, indispensáveis ao crescimento intelectual, ora refletido na harmonização entre prática docente, envolvimento estudantil e material didático de qualidade.

Dada, por assim dizer, a razoável e, quem sabe, potencial oferta de textos, é necessário voltar às inquietações norteadoras deste estudo. Assim, se compete ao docente promover a reflexão e acentuar a importância das avaliações, o que se busca com seu reavivamento e sentido? Perquirida uma entre possíveis respostas e equacionamentos, é preciso, ademais, inquirir: como o egresso e o graduando em Filosofia poderá manter e atualizar a importância das avaliações formais na hipótese de exercer a prática docente?

Ao explorar essas questões, o texto enseja, primeiramente, apresentar a emergência da reflexão, a ser conservada e enaltecida nas fases elaborativa e aplicativa, fundamentais à vida 
escolar. Ressalve-se, porém, a omissão da etapa pós-avaliativa, destinada a outro momento. Em segundo lugar, discutir-se-á a conexão entre as avaliações formais e o incentivo ao potencial discente, cujo objetivo é aprimorar habilidades, doravante despertadas nos partícipes do Ensino Médio. Espera-se, por meio deste recorte, propiciar, mesmo que minimamente, préstimos à formação de professores de Filosofia, atualmente beneficiados, assim como toda a comunidade escolar, pela alteração do Item IV, Art. 36, da Lei n. 9.394/96 (BRASIL, 1996), através da Lei n. 11.684/2008 (BRASIL, 2008) ${ }^{2}$. E ainda, resta-nos adaptar as possíveis mudanças a serem submetidas a Escola como um todo após a controversa aprovação da "Reforma" do Ensino Médio dada pela Lei n. 13.415/2017 (BRASIL, 2017) ${ }^{3}$.

\section{0 cultivo da reflexão nas fases elaborativa e expositiva. uma incumbência do docente.}

Com base nas considerações precedentes, existe o risco de a avaliação formal ser, de um lado, banalizada, isto é, conduzida por mera obrigação, e, de outro, radicalizada, como determinados simulados, processos seletivos e posturas pedagógicas rígidas. Para evitar tais inclinações, sobretudo no Ensino Médio, evocam-se “[...] metodologias de ensino e de avaliação que estimulem a iniciativa dos estudantes” (BRASIL, 1996, Art. 36, Item II). Por hora, sem elegêlas e explorá-las, busca-se fomentar, particularmente com as avaliações, maior participação discente. Desse modo, são requisitados práticas ou métodos de ensino corroborados por atividades cujo objetivo consista no aumento da reflexão, igualmente promotora (na medida do possível) da crítica e do crescimento intelectual. Aliados a estes aspectos, é imperioso considerar o "domínio dos princípios científicos e tecnológicos que presidem a produção moderna [e] o conhecimento das formas contemporâneas de linguagem" (BRASIL, 1996, Art. 36, § 1, itens I e II).

Ao direcionar tais proposições à Filosofia, será indispensável a condução de aulas expositivo-dialógicas sincronizadas às avaliações formais, cujo teor, além de reflexivo, favoreça a conceitualização, problematização e formação do pensamento autônomo. A eles acrescente-se o aprimoramento do raciocínio, associação e imaginação, respectivamente. Não obstante, compreendida como etapa fundamental da aprendizagem, a avaliação visa inserir o alunato no

\footnotetext{
2 “Altera o art. 36 da Lei no 9.394, de 20 de dezembro de 1996, que estabelece as diretrizes e bases da educação nacional, para incluir a Filosofia e a Sociologia como disciplinas obrigatórias nos currículos do ensino médio." Disponível em: <http://www.planalto.gov.br/ccivil_03/_Ato2007-2010/2008/Lei/L11684.htm\#art1>. Acesso em: 28 jan. 2014.

${ }^{3}$ A saber, “Altera as Leis nos 9.394, de 20 de dezembro de 1996, que estabelece as diretrizes e bases da educação nacional, e 11.494, de 20 de junho 2007, que regulamenta o Fundo de Manutenção e Desenvolvimento da Educação Básica e de Valorização dos Profissionais da Educação, a Consolidação das Leis do Trabalho - CLT, aprovada pelo Decreto-Lei $\mathrm{n}^{\mathrm{o}}$ 5.452, de $1^{\mathrm{o}}$ de maio de 1943, e o Decreto-Lei $\mathrm{n}^{\mathrm{o}}$ 236, de 28 de fevereiro de 1967; revoga a Lei no 11.161, de 5 de agosto de 2005; e institui a Política de Fomento à Implementação de Escolas de Ensino Médio em Tempo Integral”. Disponível em: http://www.planalto.gov.br/ccivil_03/_ato2015-2018/2017/Lei/L13415.htm. Acesso em 23/10/2017.
} 
contexto dos problemas e inquietações atuais, sem separá-los do legado filosófico clássico. Feito isso, infere-se que as atividades avaliativas são, em parte, responsáveis pelo dinamismo no trabalho escolar, resultante da observação, levantamento de hipóteses, detecção de demandas, condições de se intervir e equacionar dificuldades.

Para tanto,

Uma das dificuldades, porém, no processo avaliativo, relaciona-se com a ausência de orientações claramente explicitadas para elaboração de um programa de avaliação. Isto nos induz a questões do tipo: O que deve ser avaliado? Quando fazer a avaliação? Quem deve fazer a avaliação? Que instrumental pode ser usado para coletar e registrar informações? O que se pode fazer com as informações obtidas? (SANT'ANNA, 2001, p. 30).

Longe de oferecer respostas a essas perguntas, apesar de instigarem todo e qualquer docente, é certo que o licenciado procure preparar avaliações dotadas de critérios claros e exequíveis, favorecendo a abordagem e fixação de elementos, problemas e conceitos tipicamente filosóficos. E, ao visualizar o razoável ou satisfatório crescimento do alunato sujeito a avaliações regulares, não se descarta a maior oferta dessas atividades durante o bimestre (ou trimestre). Por exemplo, no caso do Estado do Paraná, a média é de quatorze (ou dezoito) horas-aula de Filosofia ${ }^{4}$. Nestas, por sua vez, sugere-se oferecer: 1) exercícios ou questões, 2) produção de texto em torno de um problema filosófico, e 3) a prova bimestral dissertativa ou mista. Vale constar, em todas as modalidades, logo após o cabeçalho, a enunciação instrutiva detalhada da avaliação.

Quando, por conseguinte, adotado o hábito de inclusão e observância de critérios gestores das atividades avaliativas, serão asseguradas condições de êxito, subsidiando, portanto, o avaliado. Assim, se bem redigidas e ordenadas, as avaliações proporcionam condições adequadas à constatação, equacionamento e posterior elevação intelectiva do adolescente e jovem. Ao mesmo tempo, ao se indagar sobre um programa avaliativo, não há, até o momento, orientações específicas. É provável que tal elemento seja assumido e, aos poucos, encampado e melhorado por cada disciplina da matriz curricular.

De todo modo, é aconselhável que os assuntos de maior peso tenham significativa presença nas avaliações, sem desprezar componentes secundários. Após as correções, é preciso devolvê-las, com o intuito de os estudantes identificarem deficiências e visualizarem possíveis ajustes. Já o docente, embora considere pontos pendentes, se preocupará com o direcionamento de leituras e a transposição didática. Porém, mesmo se os procedimentos acima não indicarem problemas de elevada gravidade, é necessário não se acomodar. Até porque "não há nenhum erro maior do que o de acreditar que a última palavra dita é sempre a mais correta, que algo escrito mais recentemente

\footnotetext{
${ }^{4}$ Recentemente, determinados colégios implantaram o trimestre em detrimento da tradicional divisão bimestral.
} 
constitui um aprimoramento do que foi escrito antes, que toda mudança é um progresso" (SCHOPENHAUER, 2011, p. 59).

Tal advertência pode ser assimilada enquanto interpelação, ecoando no docente, no sentido de não se conformar com a rotina das avaliações e, nos alunos, portadores, em sua maioria, de aversão - e preconceitos - em relação a essas atividades. Observadas essas afirmações, depreendese o incentivo e cultivo do sentido das avaliações ao longo da vida escolar, atribuição inseparável do conjunto de práticas docentes e, por extensão, da própria comunidade. Ademais, é oportuno reclamar o acompanhamento de pormenores traduzidos em dificuldades de aprendizagem neste decurso. A eles somem-se origens e significados das expressões, formação conceitual, embates, convergências e possíveis encaminhamentos dos assuntos selecionados nos exercícios. Afinal, as avaliações não são apenas o ponto culminante atestando aquisição satisfatória ou não de conhecimentos. Elas equivalem a instrumentos necessários e formalizados, o que não as isenta de falhas, incoerências e constante reformulação. Afinal, são produtos humanos.

Ao considerar as múltiplas linguagens e discursos presentes na Leis de Diretrizes e Bases, é preciso assegurar a coexistência entre diversas formas de expressão, desde o valor e dignidade de nossa língua, rumando aos préstimos dos idiomas histórico-naturais não vernáculos, bem como às línguas vernáculas e artificiais. Como sabido, se a Filosofia repousa sob o legado greco-romano, a menção etimológica de seus principais termos deve ser incorporada à transposição didática, despertando no alunato o gosto pela indagação das origens e significados das expressões. O efeito esperado será, em médio e longo prazo, o enriquecimento e a devida articulação do vocabulário na relação com as outras disciplinas, futuras inserções sócio-políticas e, igualmente, no mundo do trabalho.

Além do mais, na conjugação de prescrições legais ao que se imputa às avaliações formais, desponta a "[...] relação singular que a Filosofia mantém com sua história, sempre retornando a seus textos clássicos para descobrir sua identidade, mas também sua atualidade e sentido" (BRASIL, 2006, p. 27). Tal elo, quando devidamente considerado, propicia ao estudante situar-se no devir dos fatos, gênese, oscilação, formulação e variação de conceitos, seguidos da relação entre vivências e conteúdos disciplinares ${ }^{5}$ Nesta vinculação, evidencia-se a profunda convergência entre a Filosofia e a abertura de horizontes, tão limitada na educação escolar. Para poder, com efeito, reavivar o sentido das avaliações, urge ponderar:

\footnotetext{
${ }^{5}$ Solicita-se cuidado para com a preparação de aulas, exposição e, posteriormente, com as avaliações. Há o grave risco de, quando não respeitadas, as referidas desembocarem numa filosofia "light", esvaziada de referenciais (autores, problemas e conexões histórico-culturais). Sempre que possível, o professor deve utilizar textos (ou fragmentos) dos filósofos, de modo a favorecer a gradual elevação intelectual dos discentes.
} 
Apesar de sua inequívoca importância individual, no ensino de Filosofia, a avaliação não se resumiria a perceber o quanto o estudante assimilou do conteúdo presente na história da Filosofia, ou nos problemas filosóficos, nem a examinar sua capacidade de tratar deste ou daquele tema (PARANÁ, 2008, p. 62).

Reitera-se a importância de o estudante lançar-se no universo das investigações temáticas e problemáticas sem, nesta iniciação à disciplina, ter de se aprofundar na História da Filosofia. Primeiramente, deve-se vislumbrar o envolvimento e esforço do aluno ante o que fora, em tese, apresentado em sala e reforçado com leituras individuais. Contudo, se a avaliação indica, para os estudantes, o término do processo de aprendizagem mediante aferição de notas, para o professor, sinaliza o compromisso de acompanhar sistematicamente o crescimento do público. Portanto, está em jogo ampliar parte da visão de mundo dos adolescentes e jovens tornando-os, por assim dizer, melhores, responsáveis e envolvidos com problemas e inquietações que perpassam a sala de aula e o âmbito da vida privada.

Às aulas e, em seguida, às avaliações de Filosofia compete introduzir os estudantes, mediante caráter dialógico, reflexivo e interpretativo, nos desafios e problemáticas deste momento histórico. Para tanto, se forem bem conduzidas, as exposições e avaliações podem favorecer os alunos a vislumbrar nesta disciplina o que não encontram em outras. Isto porque boa parte dos currículos exige a transmissão de volumoso conteúdo, distanciando-se de vivências e relações com o grupo. Mas, ao observarem-se os diferenciais da Filosofia, o docente necessita aprimorar ainda mais as regências, pois, tal qual ocorre com variados assuntos, o público poderá estar em sincronia com a Filosofia, ansiando por absorver algumas de suas contribuições.

Sob o mesmo grau de importância, já que se reaviva o sentido de avaliar, é preciso atenção à didática utilizada, ao diálogo, florescimento da amizade e liberdade de expressão, decadentes nesta época. Cumpre, ademais, evitar que as aulas se convertam em leitura monótona, certo monólogo centralizado nas convicções do professor ou, sem desmerecer, uma reunião juvenil. Por outro lado, as temáticas a serem tratadas precisam incluir, prioritariamente, vivências conectadas a preocupações dos filósofos. Ainda é preciso que o Professor efetue, da melhor forma ordenada, a anotação de informações, definições e curiosidades na lousa, haja vista a importância da fixação de conteúdos e fomento da modalidade de memória sensório-motora. Por hora, na hipótese de essa relação ocorrer, está em voga impelir os adolescentes e jovens a desenvolver a reflexão por meio da qual se desperte a mudança de percepção e posicionamentos diante da própria vida, como também, em outros domínios.

Assim procedendo, as aulas expositivas, acrescidas de avaliações, precisam alimentar a constante inquietação e encantamento emanado do indivíduo, sua identidade, historicidade, traços 
culturais, indissociáveis do grupo e da sociedade dos quais faz parte. Até porque, diferentemente de muitas preocupações pedagógicas ou tendências ora disseminadas,

O ensino de filosofia não deve ter a pretensão de elaborar conhecimentos absolutos e definitivos, de modo a fixar o real em representações, sejam eles fatos ou ideias; deve ser mais modesto em suas intenções e se propor acompanhar reflexivamente os acontecimentos da realidade, questionando-os com problemas provisórios que exigem soluções também provisórias. (CARTOLANO, 1985, p.128).

Desta perspectiva, o diálogo firmado entre professor e alunos tem a potencialidade de reatualizar e, até mesmo, reencantar o que se entende por ato de filosofar. Dito de outro modo, as arestas, asperezas, incompreensões e desinteresses em relação à disciplina serão minimizados e, quem sabe, eliminados, ao menos em parte. Afinal, não é trivial recordar que o diálogo ou conversação é "[...] um atributo natural do ser humano" (GADAMER, 2000, p. 130), o que reforça, então, a emergência da promoção e emprego deste elemento voltado às aulas e execução de atividades avaliativas, demais trabalhos, culminando nas provas.

No caso da avaliação dissertativa, é pertinente acentuar, exceto quando o estudante não demonstra abertura para tal, o despertar para as práticas textuais. Isso não significa desprezar modalidades objetivas, mas reconhecer a dedicação dispensada à composição e aperfeiçoamento do escrito. Em todo caso, seja no Ensino Médio ou nas disciplinas propedêuticas de Filosofia, presentes em alguns cursos superiores,

[...] além de explicitar um modo de ver o mundo, o texto filosófico consiste num exercício argumentativo peculiar que ao modo de uma construção arquitetônica é deixado para a posteridade como modelo daquele modo de formular questões e solucionar problemas como é próprio à filosofia. Esse material se coloca para o seu leitor, em especial para um estudante, ao mesmo tempo como a transcrição de uma tese, sobre o mundo, por exemplo, mas também por seu caráter próprio, como uma argumentação que não só busca razões, mas se fundamenta em razões (PASCHOAL, 2013, p. 22).

Ao pressupor que o aprimoramento textual, sobretudo em termos estruturais e argumentativos, reflete a melhor visualização - e compreensão - do mundo, a avaliação é assimilada como convite e incentivo à reflexão, na qual a autossuperação não saia de cena. Assim sendo, o ato de correção, reentrega e diálogo com o discente corresponde ao ajustamento de um projeto arquitetônico em fases cruciais, determinantes ao que se presume vislumbrar em outro momento. De igual modo, com as atividades avaliativas dirigidas aos partícipes da escola média, a disciplina de Filosofia intenta abrir os horizontes da compreensão, como também elevar, na medida do possível, o nível intelectual do indivíduo. 
Para vir de encontro ao propósito supracitado, faz-se pertinente valorizar os Conteúdos

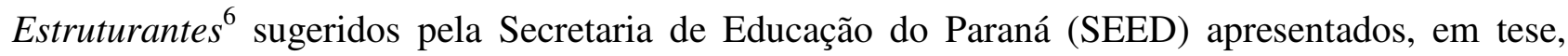
vinculados aos desafios e inquietações filosóficas. Nesta sincronização, será perquirida a harmonia entre o texto-base (clássico e contemporâneo) e as demandas manifestas pelo público. Logo após, quando aplicadas as atividades avaliativas, procurar-se-á, em observância às Diretrizes Curriculares de Filosofia, rememorar que, acima de tudo, "[...] a avaliação deve ser concebida na sua função diagnóstica e processual, isto é, tem a função de subsidiar e mesmo redirecionar o curso da ação no processo ensino-aprendizagem" (PARANÁ, 2008, p. 62). Mediante este entendimento, sem exceder na composição, ou reduzi-la à mera obrigação, busca-se enaltecer o sentido e importância desta atividade. Para fazê-la a contento, o foco primacial será a prática docente, haja vista o visível aprimoramento de habilidades interpretativas do alunato pertencente ao Ensino Médio.

\section{A avaliação enquanto promotora de habilidades e potencial discente}

Detectada a urgência da eficaz preparação e execução das avaliações voltadas às faixas etárias adolescente e juvenil, é necessário despertar a sensibilidade relativa a inquietações, problemas e desafios, tanto no concernente ao autoconhecimento, quanto à vida sócio-política. Nesse sentido, o ato de avaliar indica a averiguação do que é transmitido, assimilado e, igualmente, não entendido pelo alunato. Sinaliza também o processo por meio do qual o aluno poderá aceder à superficialidade dos conteúdos mediante esforço e investigações pessoais. Aliás, por meio de práticas interpretativas e ordenadas, será constatada a concomitância entre rememorações, associações, relações, conceitos, fatos, impressões e, em menor grau, opiniões atinentes à autossuperação, indispensáveis ao melhoramento pessoal, exercício e promoção da cidadania, consequente à aquisição de conhecimentos e tomada de postura ante o mundo, principalmente em âmbito local.

Assim compreendida, a avaliação precedida pelas aulas expositivas, indelével ao bom professor, reflete "a confluência entre a especificidade da Filosofia e seu papel formador no ensino médio [...]” (BRASIL, 2006, p. 27). Juntamente com a pertinência da disciplina, assinala-se a imputação de atribuições. Desse modo, não está em questão justificá-la, dada, em primeiro lugar, sua necessidade, mas reconhecer o valor proveniente da Filosofia. Deste emerge o saber universal seguido da reflexão acerca da existência, mesmo no caso de pessoas que, paradoxalmente, a ela não se inclinam. Ademais, considerada a necessidade da Filosofia, é oportuno rememorar que seu ensino “[...] favorece a abertura do espírito, a responsabilidade cívica, a compreensão e a tolerância

\footnotetext{
${ }^{6}$ Quer dizer, Mito e Filosofia, Teoria do Conhecimento, Ética, Filosofia Política, Filosofia das Ciências e Estética, em observância às Diretrizes Curriculares da Educação Básica, Paraná.
} 
entre os indivíduos e entre os grupos [...]” (ORGANIZAÇÃO DAS NAÇÕES UNIDAS PARA A EDUCAÇÃO, A CIÊNCIA E A CULTURA, 1995, p. 13), configurando, então, um patrimônio da humanidade, o qual reclama zelo, apreço, conservação e propagação.

Concomitante ao exposto, é preciso que o professor não desvirtue problemas, conceitos, proposições e, como um todo, o legado filosófico, ação observada em determinadas ocasiões. Defende-se, na medida do possível, o emprego de objetividade, bem-vinda às situações nas quais se manifestam convicções reproduzidas por meio de vivências do público e, também, do próprio docente. Importa destacar a proximidade firmada entre certos textos comuns à disciplina e algumas experiências, o que, sem sombra de dúvida, aproxima os estudantes da Filosofia. Não se descarta, portanto, o sentido emanado dos pensamentos e ações cotidianas. Enseja-se, por outro lado, discutir e fomentar a perpetuação de valores conjugados às responsabilidades exigidas pela vida, tanto na juventude quanto na fase adulta, ora refletidas na resolução de atividades avaliativas.

Dessas considerações extrai-se a plausibilidade das definições e questionamentos naturais à disciplina, bem como dos argumentos implicados neste exercício. É pertinente que o alunato se inteire acerca dos critérios de investigação e justificação utilizados pela Filosofia, igualmente explicitados à comunidade escolar. A esta última cumpre atentar aos pais e responsáveis, apelo estendido a todas as disciplinas da matriz curricular. Afinal, na hipótese de os pais e responsáveis saberem quais temas e problemas os filhos estudam, além de se propor a incentivá-los, haverá maior possibilidade de êxito na aprendizagem. Assim, a postura do professor - nos âmbitos pedagógico e relacional - adquire peso e, inegavelmente, oferece um fio condutor (de preferência, ordenado) às aulas e a posterior aplicação de provas.

Frente a esta articulação, não se pode omitir o fato de que, no ofício do magistério, há o constante risco de se cometer excessos e injustiças. Assim, em linhas gerais, a licenciatura em Filosofia necessita estimular a ponderação e o bom senso em seu público-alvo. Paralelo a isso, ao egresso urge a frequente observação referente ao tratamento dispensado ao público seguido da atribuição de notas e médias razoáveis, ou seja, em função do que o aluno realmente mereça.

Sem, todavia, omitir etapas anteriores às avaliações, desponta

[...] o poder arbitrário de classificar, em definitivo, sem tribunal de apelação, um educando, possui também a chave que impede (consciente ou inconscientemente) o processo de crescimento para a liberdade, para a autonomia e para o processo de crescimento. Quem aprendeu, aprendeu e quem não aprendeu fica como está. É a classificação por notas e conceitos. Deste modo, será tão arbitrário e maléfico o professor bendito que, piedosamente, facilita a vida dos alunos, classificando-os em níveis qualitativos que, ainda, não possuem como será arbitrário e maléfico o durão que, sagazmente, cria artifícios para reprovar os alunos nos exames e provas. Ambos estão trabalhando para um processo antidemocrático de verdadeiro acesso ao conhecimento e à competência necessários para a convivência em sociedade [...]. (LUCKESI, 1991, p. 173). 
Com base em ações desmedidas e, no mínimo, questionáveis, a prática docente deve ir além da aferição de notas, embora, por outro lado, isto seja necessário. A ponderação emerge, primeiramente, no relacionamento estabelecido com o público e, logo após, durante a transposição didática aliada ao domínio de turma, componentes tão importantes quanto a avaliação. Embora dotada do devido significado e legitimidade, a última nem sempre assinala o cume do processo de aprendizagem. Pelo menos em Filosofia, a não compreensão de determinado assunto, postura ou afirmação expressa, particularmente, a urgência de retomada e, ao mesmo tempo, de reapresentá-los aos alunos.

Porém, ao ater-se pontualmente nos exercícios e provas, faz-se oportuno não perder de vista que:

[...] A relação professor-aluno via avaliação, é complexa e multidimensional, à medida que representa, permanentemente, enviar e traduzir mensagens por ambas as partes. Cada um deles estará sempre interpretando o que vê e o que observa do outro, tanto em relação ao processo de aprender, como ao próprio conteúdo de aprendizagem. (HOFFMANN, 2005, p.79).

Está em questão o fomento de um profícuo diálogo em torno da ininterrupta importância da avaliação, nunca concebida isoladamente na vida escolar. Mas, para tanto, sem a formação de um ambiente cordial, dotado de requisitos mínimos a uma sadia interação, quem pode, satisfatoriamente, afirmar que estuda, ensina, avalia ou é avaliado a contento? Não obstante, o professor de Filosofia, à moda de inúmeros mestres, atua como um orientador de caminhos, salvaguardando, entre outros elementos, valores éticos, morais, cívicos e espirituais. Pela própria natureza da disciplina, aspira-se o fomento da tolerância, bem como demonstrações relativas ao convívio na diversidade e seu consequente aprendizado.

Em contrapartida, atitudes sinalizadoras de permissividade e facilitadoras, além de minarem a emancipação e a autonomia, devem ser não somente questionadas, mas evitadas. Afinal, para além dos muros da escola, que segmento da sociedade agirá com certa benevolência passiva para com o indivíduo? Do mesmo modo, não se enseja a adoção de práticas repressivas que, historicamente, macularam as aulas expositivas e as provas. Conforme sabido, ainda na atualidade, a escola sente ressonâncias de ações repressoras e, até mesmo, totalitárias. Dessa maneira, evocar a liberdade e os valores democráticos não significa que o professor abra mão daquilo que sua disciplina - neste caso, a Filosofia - possui de mais precioso: vocabulário, textos e autores, termos técnicos, problemas e conceitos em proveito de modismos e, com a mesma gravidade, depreciações didáticas as quais, infelizmente, não contribuem em nada para a elevação intelectiva do público.

Efetuado o presente posicionamento,infere-se que, sobretudo em Filosofia, a “[...] avaliação é uma apreciação qualitativa sobre dados relevantes do processo de ensino e aprendizagem, que 
ajuda o professor a tomar decisões sobre sua atividade profissional.” (LIBÂNEO, 1992, p. 196). Uma vez prevista e aplicada a avaliação procura contemplar os componentes de maior peso apresentados em um período, como o bimestre, por exemplo. Em outros termos, para ser bemsucedida, juntamente com o envolvimento discente, a atividade avaliativa oportuniza ao professor constatar limites, entraves e, inclusive, deficiências alusivas aos conteúdos, a saber, o material didático, a participação da classe e a transposição. Em síntese, proporciona reflexão e crescimento, de modo sincronizado, ao alunato e ao docente, cabendo - desde que em observância à razoabilidade - punições e, porque não dizer, em determinados casos, reprovação.

Quando assumida de forma processual, isto é, ministrada mediante uma sequência, as atividades avaliativas oferecem, entre outros benefícios, “[...] a arte de quebrar a naturalidade com que normalmente são utilizadas as palavras e os conceitos. Um modo de reflexão que não se restringe aos objetos do conhecimento, mas busca compreender o próprio ato de conhecer" (PASCHOAL, 2013, p. 19). Contudo, apropriar-se de palavras não assinala sabê-las de memória, seja um termo ou frase. É imprescindível internalizá-las, compreendê-las, adquirir a capacidade de articulação com outros significados e contextos historicamente constituídos, culminando, então, na acurada capacidade de raciocinar e pensar coerentemente. Para isso, urge perpassar a estaticidade do texto e das próprias avaliações, sinalizando para a vida, o sentido e a dinâmica das palavras nele contidas. Trata-se de, por assim dizer, despertar habilidades, em boa parte das vezes, adormecidas no indivíduo.

Assim, há que se assumir, por um lado, a predisposição e, em certos casos, a facilidade do público - mesmo que seja uma minoria - em adentrar no universo textual, exceto em passagens inóspitas e íngremes. Em todo caso, louva-se tal iniciativa, nem sempre valorizada pelo professor. No entanto, quando forem detectadas ações frustradas atinentes à compreensão dos textos, faz-se oportuna a intervenção docente com vistas à aproximação do que ocupa a pauta das aulas. Afinal, mediante a dureza e complexidade de fontes, o público tende a se frustrar inicialmente com o assunto e, em seguida, com a disciplina e o curso por inteiro. Com o intuito de evitar experiências malsucedidas com a Filosofia, reclama-se a condução e mediação docentes. Estas nunca devem ou deverão perder de vista a gestação e o cultivo de habilidades voltadas aos diversificados perfis de alunos. E ainda, justamente a avaliação, independentemente da modalidade, atesta a importância de revisar e adaptar não somente a composição dos exercícios, mas, igualmente, a prática de ensino.

\section{Considerações finais}

Ao abordar a avaliação, foi observada, mesmo que sucintamente, a importância deste conjunto de exercícios regulares presentes na vida escolar. De modo paralelo, depreendeu-se a 
íntima conexão entre a oferta dessas atividades precedidas pelas aulas expositivas, preferencialmente, bem preparadas e conduzidas. Nesse sentido, sugeriu-se ponderar a duração das regências e avaliações, de modo a tornar a frequência destas últimas ainda maior. Conforme assinalado, na hipótese de adoção dessas orientações, as chances de se vislumbrar o desenvolvimento de competências e habilidades do alunato será expressiva. Ao mesmo tempo, tal ação respaldará a metodologia de ensino adotada pelo professor, pois, de fato, corrobora a execução de conteúdos nas atividades avaliativas.

Assim procedendo, na Filosofia, para além da obrigatoriedade estipulada pelo Plano de Ensino e pela Política Escolar, a avaliação passou a ser entendida como averiguadora do nível de aprendizagem obtido ou não pelo indivíduo, constatando desde pequenas incoerências até os mais graves e, possivelmente, evitáveis erros. Desse modo, foi enaltecida a consideração da avaliação formal, tradicionalmente indissociável da educação escolar. Para valorizá-la à altura, solicitaram-se a inclusão de critérios norteadores logo abaixo do cabeçalho, com o intuito de explicitar em que a ela consiste. Juntamente com os enunciados de comando, urgem a insistência e reavivamento da parte do aplicador. Ademais, no âmbito de uma relação cordial, (nunca permissiva), o docente deve imprimir seriedade à entrega, aplicação, correção e, finalmente, distribuição e comentários dos trabalhos e provas.

Afinal, à moda de um ritual, (seja religioso, político ou de outros segmentos), no qual a ação - apesar de repetitiva - transcende a mecanicidade do cotidiano, a aplicação das provas deve oportunizar o desafio à autossuperação conjugada à detecção de limites em face da disciplina. Mesmo se, na pior das hipóteses, a "Reforma" do Ensino Médio reduzir a quantidade de anos letivos de Filosofia, ou se a mesma for ofertada sob formato de Oficinas ou outras atividades correlatas, os critérios, peculiaridade, sentido e valor das avaliações devem persistir. ${ }^{7}$ Análoga à dita execução - e tão importante quanto as avaliações - desponta a manutenção de seu sentido. Infelizmente, no momento atual, defere-se o desencantamento para com o magistério e o ato de estudar enquanto tal. Sobretudo no Ensino Médio, etapa elencada, a presente manifestação assinala reflexos decorrentes de várias crises, as quais perpassam este recorte, abalando também as instituições escolares. Dado que as últimas não são formadas apenas por alunos, é previsível que demais pessoas, inclusive os professores, se influenciem por não correspondências e, então,

\footnotetext{
${ }^{7}$ Infelizmente, sem a aprovação da BNCC (Base Nacional Curricular Comum), ainda não se sabe como será a segunda parte do Ensino Médio, resultante da "reforma" efetuada em 2016. Há, assim, menção à área denominada Ciências Humanas, na qual figura a Filosofia. Não obstante, se a BNCC não a prescrever com clareza, a Filosofia poderá ser dissolvida em outras matérias, tal qual fora visualizado no ensino brasileiro.
} 
absorvam o problema. Cumpre, ante a crise, detectar as causas e, dentro do possível, contorná-la e, quem sabe, superá-la.

Mas de que forma ou com quais instrumentos isso é, via de regra, possível? Em primeiro lugar, é preciso que, munido de persistência e comprometimento com o ofício, o docente internalize o valor da avaliação para toda e qualquer pessoa, a ponto de colocar-se no lugar dos que estão efetuando esta atividade. Em outros termos, compete-lhe atribuir e atualizar o sentido do que faz, assimilando a avaliação formal, de um lado, como indicadora de aspectos pendentes e, de outro, como o instrumento responsável pela constatação de deficiências, particularmente as de fixação e discussão de conteúdos filosóficos, sem dúvida relacionados às outras disciplinas e inúmeros problemas humanos extraclasse.

Segundo as presentes considerações, tendo em vista que a maioria das escolas emprega a aula tradicional (o que não significa menosprezar modalidades adversas à mencionada), os recursos atinentes à promoção de avaliações reflexivas dizem respeito à salutar indagação e contestação do comodismo imperante. Ora, quando selecionados determinados textos, efetuado o planejamento e pressuposto o envolvimento discente, observar-se-á a condução das avaliações de modo a afastar-se do desencantamento ora aludido. E, ainda, munido do que dispõem as Orientações Curriculares do Ministério da Educação conjugadas às Orientações Curriculares da Secretaria de Educação do Paraná, preservar-se-ão e, provavelmente, serão incrementados os trabalhos e avaliações de Filosofia.

Para tanto, torna-se imperiosa a concepção do professor como mediador e indicador de caminhos. Ele não é, tal qual tristemente se recorda, o depositário exclusivo do saber; nem, tampouco, o indivíduo que, para se aproximar do público, irá vulgarizar os conteúdos, colocando uma máscara sobre a face da Filosofia e, por extensão, de qualquer outra disciplina. Antes, com base na perspectiva apresentada, o docente se caracteriza como o indivíduo em constante busca, portador de grandes dúvidas, dotado de certo ceticismo e senso crítico ante posturas determinadas e inflexíveis. Também se coloca em abertura para questionamentos, discordâncias e apelos à revisão na prática de ensino como um todo, o que engloba as avaliações, atividades que nem sempre indicam o esperado ou demonstram o êxito ideológico dos - independentes de quais forem poderes constituídos e tendências pedagógicas dominantes. 


\section{Referências}

BRASIL. Lei no. 9.394, de 20 de dezembro de 1996. Estabelece as diretrizes e bases da educação nacional. Disponível em: http://www.planalto.gov.br/ccivil_03/Leis/L9394.htm>. Acesso em: 28 jan. 2014.

. Lei $\mathbf{n}^{\mathbf{0}} \mathbf{1 1 . 6 8 4}$, de 02 de junho de 2008. Altera o art. 36 da Lei ${ }^{\circ}$ 9.394, de 20 de dezembro de 1996, que estabelece as diretrizes e bases da educação nacional, para incluir Filosofia e Sociologia como disciplinas obrigatórias nos currículos do ensino médio. Disponível em: <http://www.planalto.gov.br/ccivil_03/_Ato2007-2010/2008/Lei/L11684.htm\#art2>. Acesso em: 28 jan. 2014.

Lei $\mathbf{n}^{\mathbf{0}}$ 13.415, de 16 de fevereiro de 2017. "Altera as Leis $\mathrm{n}^{\mathrm{os}}$ 9.394, de 20 de dezembro de 1996, que estabelece as diretrizes e bases da educação nacional, e 11.494, de 20 de junho 2007, que regulamenta o Fundo de Manutenção e Desenvolvimento da Educação Básica e de Valorização dos Profissionais da Educação, a Consolidação das Leis do Trabalho - CLT, aprovada pelo Decreto-Lei $\mathrm{n}^{-}$5.452, de $1^{\underline{0}}$ de maio de 1943, e o Decreto-Lei $\mathrm{n}^{\mathrm{o}} 236$, de 28 de fevereiro de 1967; revoga a Lei n⿳⺈⿴囗十一11.161, de 5 de agosto de 2005; e institui a Política de Fomento à Implementação de Escolas de Ensino Médio em Tempo Integral.” Disponível em: http://www.planalto.gov.br/ccivil_03/_ato20152018/2017/Lei/L13415.htm. Acesso em 23/10/2017.

Ministério da Educação e Cultura. Orientações Curriculares para o Ensino Médio. Ciências Humanas e suas tecnologias. Vol. 3. Brasília: MEC, 2006. p. 7-40. Disponível em: <www.portal.mec.gov.br/seb/arquivos/pdf/book_volume_03_internet.pdf>. Acesso em: 10 fev. 2013.

CARTOLANO, T. Filosofia no ensino de $2^{\circ}$ grau. São Paulo: Cortez, 1985.

GADAMER, H.-G. A incapacidade para o diálogo. In: ALMEIDA, C. FLICKINGER, H.-G. \& ROHDEN, L. Hermenêutica Filosófica. Nas trilhas de Hans-Georg Gadamer. Porto Alegre: Ed. da PUCRS, 2000.

HOFFMANN, J. O jogo do contrário em avaliação. Porto Alegre: Mediação, 2005.

LIBÂNEO, J. C. Didática. São Paulo: Cortez, 1992.

LUCKESI, C. C. Filosofia da educação. São Paulo: Cortez, 1991.

PARANÁ. Secretaria de Estado da Educação. Diretrizes Curriculares da Educação Básica. Disciplina de Filosofia. Curitiba: Jam3 Comunicação, 2008.

PASCHOAL, A. E. Da especificidade da Filosofia ao seu ensino. Revista do NESEF, Desafios epistemológicos e políticos da Filosofia na escola básica, Curitiba, v . 3, n. 3. p. 17-25, jun./set. 2013.

SANT'ANNA, I. M. Por que avaliar? Como Avaliar? Critérios e instrumentos. Petrópolis, RJ: Vozes, 1995.

SCHOPENHAUER, A. A arte de escrever. Porto Alegre: LP\&M, 2011.

ORGANIZAÇÃO DAS NAÇÕES UNIDAS PARA A EDUCAÇÃO, A CIÊNCIA E A CULTURA UNESCO. Declaração de Paris para a Filosofia. [Trad. do original Philosophie et Démocratie dans le Monde - Une enquête del UNESCO. Librairie Génerale Française, 1995. p. 13-14]. Pensando bem... [blog], Núcleo de Pesquisa em Filosofia e Educação, Universidade Federal de Juiz de Fora, s.d. Disponível em: $<$ http://www.ufjf.br/pensandobem/files/2009/10/Declara\%C3\%A7\%C3\%A3o-de-Paris-para-a-FilosofiaUNESCO.pdf>. Acesso em: 12 jan. 2014. 


\section{Formal evaluation in philosophy: considerations adresseds to the high school.}

\begin{abstract}
The text approaches the formal evaluation and it discusses the resumption of meaning along the development and operationalization of this activity. Focuses on the Discipline of Philosophy, offered in High School (General Education and Vocational College) and indicates the condition of greater proximity between students and the Program Contents. Therefore, it seeks exalt the dialogue and the mediation, indelible capabilities to the teacher, directing them for the evaluations activities. In so doing, considered the obligation of those referred in this and others phases of school education, in way the teacher may cultivate and, constantly, upgrade the meaning of the formal evaluations, especially in the steps of preparation and application? In order to offer a propositive response, resorts to the specific way, the National Curriculum Guidelines, in part designed to Philosophy. However, not to incur general enunciations, or that flee the question, will be conjugates the indications stemming to the Basic Education Curriculum Guidelines/SEED-PR. Through the present convergence, contributions received will be directed to settle the claims arising in the evaluation field, inevitable to the undergraduates and graduates of the Degrees in Philosophy.
\end{abstract}

Keywords: Formal evaluation. Philosophy. High School.

\section{Marcelo Prates}

E-mail: marceloprates1@gmail.com

Antonio Carlos Persegueiro

E-mail:prof.antoniuscarlus@gmail.com
Evaluation formelle dans la philosophie : considerations adressees a la lycee.

\section{Résumé}

Le texte traite de l'évaluation formelle et examine la reprise du sens avec la préparation et de l'opérationnalisation de cette activité. Se concentre sur la discipline de la philosophie offert en Lycée (Enseignement Général et le Technicien Supérieur) et indique la condition de la plus grande proximité entre les élèves et le Programme. Pour les deux, il cherche à exalter le dialogue et la médiation, des capacités indélébiles à l'enseignant, en les dirigeant pour les activités d'évaluation. Ce faisant, a examiné l'obligation de ceux qui sont mentionnés dans la présente et d'autres phases de l'éducation scolaire, comment l'enseignant peut cultiver et mettre à jour constamment le sens des évaluations formelles, en particulier dans les étapes de préparation et d'application ? Afin de fournir une réponse propositionnelle, d'une manière spécifique Il utilisera les Lignes Directrices du Programme National, dans la partie destinée à la philosophie. Cependant, pour ne pas encourir des énoncés généraux ou de fuir à la question, conjuguera les indications qui s'inscrivent dans les Lignes Directrices $d u$ Curriculum pour l'Éducation de Base / SEED-PR. Par la présente convergence, les contributions reçues seront destinées à régler les demandes résultant dans le domaine de l'évaluation, inévitable aux étudiants et diplômés des Cours de Philosophie.

Mots-clés: Évaluation Formelle. Philosophie. Lycée.

Enviado em: 08/08/2017

Versão final recebida em: 22/10/2017

Aprovado em: 30/10/2017 